\title{
Psychedelics and the media in the Visegrad countries*
}

\author{
ORSOLYA FEHER** \\ Department of Communication, University of Vienna, Vienna, Austria
}

(Received: January 19, 2018; revised manuscript received: June 15, 2018; accepted: June 18, 2018)

\begin{abstract}
Background and aims: This paper aims to shed light on the prevailing public narrative regarding psychedelics and the media's role in cultivating it. The study focuses on the four states of the Visegrad Alliance, whose members gained independence from the Soviet Union and later joined the European Union simultaneously. Thus, ominous substances were introduced to their drug markets and wider societies around the same period, yet their current drug policies and international stances on drug related issues differ vastly. The paper argues that although the so-called psychedelic renaissance is rather visible and mediatized in wealthy occidental countries, due to a harsh stigma surrounding psychedelics in the former Eastern Bloc, the state of psychedelic science is lagging behind its potential. Methods: Applying mixed methods of qualitative and quantitative, primary and secondary data collection, the effects of mass media, and the impact of the respective cultural and legal environments of each country are compared and analyzed, using multiple linear regressions, mediation, and moderation analyses. Results and conclusions: As frequent viewers of television demonstrate a lower level of informedness and a more negative attitude toward psychedelics, the findings of this paper are parallel to what is a frequent topic among psychedelic researchers and one that poses important institutional, financial, and reputational challenges on the progress of science. The vision of this study is to foster a public discourse that is more balanced and in which real and relevant risks are addressed.
\end{abstract}

Keywords: cultivation theory, psychedelic stigma, public opinion, mass media, communication science

\section{INTRODUCTION}

There exist countless studies to prove how media narratives shape political discourses by implementing frameworks that consumers can adopt and institutions can embrace through policy (Brown, 2013; Glasser \& Salmon, 1995; Lewis, 2001; Rothstein \& Finnigan, 2015). As it provides narrative and guides interpretation (Cohen \& Weimann, 2000), public opinion is heavily influenced by the images and messages transmitted through popular media (Kruger \& Wall, 2001). The manner in which media presents certain issues thereby influences our common understandings and thus attitudes toward societal issues, such as crime or drug use (Forsyth, 2001). Looking into the issue of mass media coverage is an important step toward understanding perceptions and concerns regarding drugs (Forsyth, 2001; Körner \& Treloar, 2004) and the corresponding advances in science.

The salient discourse narrates drug-related issues in ways that highlight the immorality and individual's responsibility of drug use (e.g., Rothstein \& Finnigan, 2015; Szasz, 2001). The harsh attitudes toward psychedelic drugs that emerged in the past 60 years (Williams, 1999) have been argued to rely on the mediatized image of narcotics, over actual statistical volume of emerging problems in society (Beckett \& Sasson, 2004) or scientific findings (e.g., Krebs \& Johansen, 2013; Lüscher \& Ungless, 2006; Nichols, 1999/2000).
This paper aims to assess the public perception of media narratives surrounding psychedelic substances and its implications for the prevailing public attitude with a focus on television (TV) in the Visegrad countries. The Visegrad Alliance is the concourse of the four former satellite states of the Soviet Union - Czech Republic, Hungary, Poland, and Slovakia - that gained independence from the Union of Soviet Socialist Republics (USSR) at the same time period and subsequently joined the European Union as a fruit of a joint pursuit. This led to the simultaneous opening of the market to ominous substances and thus their introduction to wider society. However, the current drug policies and international stances on drug-related issues of the V4 differ vastly. Despite the complex political relations and the interesting cultural community of the region, the apparent discrepancy between the scientific promises of medical implications and the negative media coverage has not yet sparked an academic interest in examining the psychedelic stigma in Central Europe.

In the paper, it is argued that characteristics of drug depiction in popular media have created an environment

\footnotetext{
*This is a research paper on the cultivation effect of TV consumption on public opinion regarding psychedelic substances.

** Corresponding address: Orsolya Feher; University of Vienna, Mentergasse 3/8, Vienna 1070, Austria; Phone: +44 677 61752309; E-mail: ors.feher@gmail.com
} source are credited, a link to the CC License is provided, and changes - if any - are indicated. 
that promotes a hostile attitude in relation to drugs, particularly psychedelics, and that this relationship is moderated by the cultural and the legal contexts of the countries.

\section{THEORETICAL BACKGROUND AND THE IMAGE OF PSYCHEDELICS}

Cultivation theory, the guiding concept of this project, studies the "relationship between institutional processes, message systems and the public assumptions, images, and policies they cultivate" (Gerbner, 1970, p. 71). In developing the theory, Gerbner and Gross (1976) collected data on the rate of harmful stereotypes portrayed in network TV and argued that TV had an enculturation effect on people. Cultivation suggests that, although many times the viewer is unaware of the extent to which they absorb media, mass communication possesses a significant influence on the attitudes and beliefs of society, and those who absorb more are more influenced.

Mass communication has been suggested to shape the collective mind by researchers from various fields (e.g., Surette, 1992), and as TV overcame historic barriers, such as social status, mobility, and literacy, it is said to have become a primary medium to convey culture (Gerbner, 1993). Amid several studies claiming that people use the information they receive from the media to construct a view of their world, regardless of the reliability of the source (Bissler \& Conners, 2012; Dowler, 2003), it has also been found that most TV programs serve to reinforce the prevailing social order and follow a pattern of system stabilizing images (Schoenbach \& Becker, 1995). This mechanism and the impact of TV are particularly interesting, considering their power of stirring public opinion regarding topics that have high societal importance (McCombs, 1997), such as drugs and drug use.

When attempting to understand TV's effect on attitudes toward psychedelics, this study applies cultivation theory to assess the effect of the aggregate of TV messages on audiences' notion of psychedelics, and by extension, public opinion on the matter.

Although countless researches into the therapeutic advantages of psychedelic substances suggest that psychedelics can provide valuable aid to those seeking assistance with psychiatric conditions (e.g., Alper \& Lotsof, 2007; Carhart-Harris et al., 2012, Nichols, 2016; Vollenweider \& Kometer, 2010), the current public discourse broadcasts the use of these drugs to the general population by framing them in a criminal, deviant, or plain socially undesirable context. When it comes to drug use and/or drugs of any kind, the existing media narrative predominantly focuses on the criminal aspects (e.g., Belackova, Stastna, \& Miovsky, 2011) and understands drug use in a societal judgement context (e.g., Acevedo, 2007; Granfield \& Cloud, 1996; Noto, Pinsky, \& Mastroianni, 2006; Welch, Fenwick, \& Roberts, 1998).

And, even though this criminalizing model slowly loses its prevalence in academic circles, it is very much present and even dominant in public opinion in Central European states (Demetrovics \& Balázs, 2004; Szasz, 2001). Thus, besides securing funding, ethical approval of such research is not without significant obstacles (O'Neill, 2014).

This paper asserts that the mass media's heuristic role as the primary source of information and for understanding science and innovation (Brossard \& Nisbet, 2007; Morgan, Shanahan, \& Signorielli, 2012) largely contributes to the existence of the psychedelic stigma, which results in institutional, financial, and reputational challenges for psychedelic science (e.g., Sewell, 2006).

Although increased interest and coverage of psychedelic scientific advances could have been observed in the past few years, mainly in the United States (e.g., Boseley, 2016; Burns, 2015; Jarnow, 2016), there are still notorious distortions when it comes to psychedelics, especially outside of wealthy occidental countries. This paper argues that the so-called "psychedelic renaissance" has not reached Central Europe en masse, despite an indisputable need for a modernized approach to mental health and treatment for problematic drug use in the region [based on McCollam (2008), Mental Health OECD (2017) reports, and EMCDDA (2015) data].

\section{THE VISEGRAD FOUR (V4)}

The study focuses on the developing Central European region, specifically the V4. The V4's respective histories have been intertwined throughout the years, including numerous territories being ruled by the Habsburg Empire and its successors at various times until World War I. During the Cold War, the V4 were "satellite states" of the Soviet Union, and the Visegrad Group was established in 1991, following the collapse of the USSR. In 2004, all four countries have joined the European Union on the same day, as a fruit of a joint pursuit.

Despite the shared historical and cultural background, when it comes to drugs, apparent differences in both policy and culture can be observed at high-level international political statements and implementations of national drug strategies (Krawczyk, 2017).

Before the end of the Soviet regime, drug use was far from being on top of the political agenda in the socialist countries. Sovereign political models, institutions, and policies on drug-related activities have only been formed rather recently with the adaption of the widespread prohibitionist Western models (Cohen, 1993). This criminalizing model stayed prevalent in the former Eastern Bloc until today, and drug consumption is still mostly seen as an offense and thus rendered as a problem for law enforcement and judiciary (Szasz, 2001).

This project surveys the prevailing TV consumption habits, the general public's attitude toward psychedelic substances, and the moderating effect of the different cultural and legal contexts. The results could offer an insight into the power of TV in the former Eastern Bloc, despite some local research into the stigma of drug use, the differences in approaches and their effect on forming attitudes have not yet been studied. 
The central question the paper poses is the following:

How does the cumulative impact of TV consumption affect the attitude toward psychedelics in the Visegrad countries?

As a result of continual mentions of illicit drugs in a moral-judgement context, this paper hypothesizes that people internalize the images they encounter, i.e., a cultivation effect takes place as such:

H1: TV exposure is positively correlated to a negative attitude toward psychedelics.

Consequent to the previously outlined differences across the four member states, both in regard to cultural and legal environment, the paper also hypothesizes that

H2: The cultivation effect differs by country in the Visegrad Group.

$H 3 a$ : The cultivation effect of $H 1$ is moderated by the cultural context of each country's drug scene, respectively.

$H 3 b$ : The cultivation effect of $H 1$ is moderated by the legal environment of each country's drug scene, respectively.

The study expects to find TV consumption effects to be stronger in countries where the legal system is more restrictive and the cultural environment is less adept at dealing with the possible risks associated with the recreational use of psychedelics. In an environment, where the juristic system echoes the messages of mass media and the psy-culture is less proficient on harm reduction, negative portrayal is expected to seem more realistic.

\section{METHODOLOGY}

\section{Sample}

A non-probability snowball sampling method is applied with an aim for a heterogeneous pool. The outcome of ominous data collection resulted in 720 valid cases. Consequentially, the sample could be described as a rather diverse pool with participants ranging from 15 to 80 years of age where the mean age is 32.5 years with a steady distribution of gender, as 393 participants (54.6\%) were male. Distribution of collected data across countries and further descriptive statistics are included in Table 1.

\section{Measures}

Media variable - TV consumption

The media variable, assessing the extent of media consumption, was measured on four separate items that were constructed for the purpose of this research and asked the participants to choose from five options (nothing at all, less than $1 \mathrm{hr}, 1-3 \mathrm{hr}, 3-6 \mathrm{hr}$, and more than $6 \mathrm{hr}$ a day) that best describe how much time they spend (a) actively watching TV on an average weekday, (b) on an average weekend day, (c) how much they estimate the TV is on in the background on a weekday, and (d) on weekends, i.e., their passive consumption of TV. A new variable of the above scales was then calculated in order to express the summing of TV consumption with as Cronbach's $\alpha$ of .893.

An important factor to consider when probing media consumption is the emergence of on demand TV online. Since the researchers have come across several reports on the Internet's potential cannibalization of the TV audience (e.g., Nielsen, 2010), this paper finds it important for the participants to report on their consumption of programs produced for TV but transmitted through other channels as well. Participants therefore were repeatedly reminded to consider their answers keeping in mind the material, regardless of the device on which they consume.

\section{Attitude}

The dependent variable's attitude toward psychedelics was measured across four scales that assessed the respondents' (a) perception of the danger of psychedelics, (b) approach to recreational drug use, (c) attitude toward medical applications of psychedelic substances, and (d) stances on their regulation. Every scale had five category of responses (ranging from $1=$ completely disagree to $5=$ completely agree), where all the statements were worded negative or reverse coded, retrospectively, so that the higher scores on each of the scales indicate a more hostile attitude toward psychedelics. A new variable, a composite scale of the above scales, was then calculated in order to express a general attitude toward psychedelics with a good reliability index (Cronbach's $\alpha=.943$ ).

The attitude toward recreational use was measured across nine items, of which, upon using a simple reliability analysis, six items loaded on the same factor with a Cronbach's $\alpha$ of .915 , indicating a highly consistent scale. On ominous five items, respondents indicated on a 5-point scale on how much they would be bothered (a) by someone in their

Table 1. Descriptive statistics per country

\begin{tabular}{lcccc}
\hline & Czech Republic & Hungary & Poland & Slovakia \\
\hline$N$ & 283 & 177 & 97 & 163 \\
Mean age (years) & 28.72 & 42.23 & 28.66 & 30.41 \\
Percentage of male participants (\%) & 51 & 44 & 64 & 47 \\
Mean level of education $^{\mathrm{a}}$ & 3.27 & 3.79 & 3.72 & 4.11 \\
Admitted to previous experience (\%) $_{\text {Mean TV consumption (hr/week) }}^{33}$ & 6.91 & 6 & 40 & 7.73 \\
\hline
\end{tabular}

Note. ${ }^{\mathrm{a}}$ Level of education was measured on a 7-point Likert scale, where $1=$ elementary school, $2=$ high school/gymnasium/vocational school, 3 = adult education, $4=$ finished BSc/BA level degree, $5=$ finished $M S c / M A, 6=$ finished PhD/doctrate level degree, and $7=$ other . 
environment under the influence of psychedelics, (b) by someone offering them psychedelics, (c) by someone in their environment under the influence of cannabis, (d) by someone in their environment under the influence of some narcotics, (e) if they avoid events/places where they know people might be consuming psychedelics, and (f) whether they would contact the police (or in case of a minor, parents) if someone would offer them psychedelics.

Perception of danger of psychedelics was measured on a 9-item scale, where three loaded on one component with good reliability, i.e., a Cronbach's $\alpha$ of .797. The three items, somewhat blatantly, measured the respondents' evaluation of cannabis, psychedelics, and non-hallucinogenic drugs, in regard to how dangerous they think the use of them are.

The attitude toward medical use of psychedelics was measured on a scale of six items, two of which asked whether the respondent thinks taking psychedelics in an appropriate environment can be beneficial to (a) mental and (b) physical health - these loaded on the same factor with a Cronbach's $\alpha$ of .901 . Due to a glitch in the Czech translation, the second variable regarding physical health had to be deleted when computing the sum of attitude scale.

Participants' opinion on current drug policies, focusing on regulation, was measured on a 4 -item scale, where all loaded on one component with a Cronbach's $\alpha$ of .752 . Here, participants could indicate the extent to which they agree with the following statements: (a) law enforcement should be stricter when it comes to psychedelics, (b) the only way to tackle the drug problem is through legislation and law enforcement, (c) regular consumers of psychedelics are criminals, and (d) drug addiction is only the person's fault. Given the sensitivity and uniqueness of the topic, after the media consumption habits section in the survey, a short definition was included in the questionnaire that explained what psychedelics were referencing their long history of use, legal status, and a single sentence indicating their potential benefits as medicine and use in psychotherapy. Two control questions followed the definition page, asking participants (a) about the novelty of information, i.e., if they have read anything new on the previous page with an opportunity to expand on what exactly have they learned and (b) whether they themselves have taken psychedelic substances, with an option to elaborate on the experience - this data, however, was not used in this study.

\section{Informedness}

The state or quality of being informed on the scientific use of psychedelics is expressed in the study under the umbrella term of "informedness" that was measured on a 5-item, selfassessing scale. On the informedness scale, participants could indicate to what extent they think they are up to date (where $1=$ absolutely not and $5=$ absolutely) on the topic of (a) drug policy, (b) informed about psychedelic research, (c) psychotherapeutical advances, (d) whether they have heard of any psychedelic research, and (e) whether they thought psychedelic research should be banned - however, this item was excluded in the final analysis. This variable was measured individually and not grouped into the composite attitude scale as the intention of this measurement would not fit logically into the composite one, and items 1-4 made up a fairly reliable scale independently with .751 for Cronbach's $\alpha$.

\section{Moderators}

In order to test whether the $(\mathrm{Ma})$ cultural or $(\mathrm{Mb})$ legal environment of a country plays a significant role in forming public opinion, the researchers conducted secondary research and a series of semistructured in-person and Skype interviews with journalists and policy advocates in each country. Altogether, six interviews were conducted by experts who have been active in high-level political forums and responded to the researcher's invitation for participation. The interviews consisted of five clusters, where interviewees assessed (a) the state of psychedelic science and the public's awareness of ominous studies, (b) available harmreduction measures, (c) the recreational scene, and (d) the prevailing image of psychedelics in the media - supported by some empirical evidence.

Each nation was evaluated by the researcher on consistent, 5-point scales reflecting the above values (Appendix).

A new variable was then calculated, which determined how facilitating the cultural environment was for the formation of hostile attitudes. Following a cross-checking conversation with each interviewee and the study's supervising professor, the evaluation of each country was left to the discretion of the researcher, where 1 was a very hostile and 5 indicated a psychedelic-friendly cultural predicament.

The category to determine the legal context was based on secondary data: publications recommended by the interviewees and publicly available data by the European Monitoring Centre for Drugs and Addiction. Here, the countries were evaluated on a 5-point scale that expressed the harshness of drug policies and the values were then assigned to each data row, based on the participant's nationality. The scoring was arbitrary but discussed in length with the interviewees and approved by their colleagues who work on the field of drug policy.

\section{Control variables}

A number of demographic variables such as gender, age, residence, and level of education are employed in the analysis in order to ensure that media effects are properly measured. In addition, respondents were asked a polar question to indicate their familiarity and personal experience with the authorities and psychedelic substances, respectively, as media sources will be more meaningful when direct experience is lacking (Schnauber \& Meltzer, 2005).

\section{Analytic strategy}

The study employs multiple linear regressions, using SPSS in order to test whether or not media consumption predicts the attitude toward psychedelics $(H 1)$ and differences of the cultivation effect by country $(\mathrm{H} 2)$. For the test of $H 3$, a mediation analysis is conducted, using the process macro (Hayes, 2012) where the independent variable is media 
consumption, the dependent is attitude toward psychedelics, and the moderating factor is informedness. For testing the moderating effects of $(\mathrm{H} 3 \mathrm{a} a)$ cultural context and $(\mathrm{H} 3 \mathrm{~b})$ legal environment, a different model of the process macro is applied.

\section{RESULTS}

The analytic strategy to test the first hypothesis was to conduct a linear regression to see whether and how people's attitude varies, depending on their media consumption habits, while controlling for demographics and personal experience (i.e., familiarity) is demonstrated in Table 2. In the first model, the effect of TV consumption on attitude without control variables is examined, which explains $18.8 \%$ of the variance. The second model includes control variables of previous personal experience with psychedelic substances and demographics. Although the power of influence is less, the second model explains considerably more, $29 \%$ of the variance with high significance, where all the control variables showed a significant predicting effect, except for the level of education.

As a part of this analysis, the correlation between the amount of TV watched and the level of informedness was also tested with similar results; the fourth model that included the control variables explains $13.5 \%$ of the variance, which is higher than the third model of $7.6 \%$, while both are highly significant. Thus, based on these linear regression models, it can be argued that, in general, those who watch more TV are more likely to be less informed and have a negative attitude toward the substances in question.

Upon testing the second hypothesis, multiple linear regressions per country were run to examine the differences of the cultivation effect in each country and, as Table 3 presents, some interesting findings emerged $-\mathrm{H} 2$ can be nonetheless accepted.

In the process of testing the second hypothesis, a multiple linear regression analysis was also conducted to examine whether TV consumption and nationality have a significant effect on attitudes, where the countries were assigned a value based on their average score for cultural and legal environments (Table 4). The results show that a model with these two independent variables explains ca. $26 \%$ of the variance and remains highly significant: $F(2,702)=121,296$, $p<.001, r^{2}=.257$.

To examine the research question of $H 3 a$ and $H 3 b$, a oneway analysis of variance (ANOVA) was conducted to determine if there is a significant difference on the attitudes by legal and cultural environments. The independent

Table 2. Multiple linear regression report

\begin{tabular}{|c|c|c|c|c|c|c|c|}
\hline Model & Dependent variable & Independent variable(s) & $r^{2}$ & $\beta$ & $F$ & $p$ & VIF \\
\hline 1. & Attitude & TV consumption & .188 & 0.434 & 1,713 & .000 & \\
\hline \multirow[t]{6}{*}{2.} & \multirow[t]{6}{*}{ Attitude } & TV consumption & .290 & 0.363 & 6,696 & .000 & 1.082 \\
\hline & & Gender & & 0.232 & & .000 & 1.029 \\
\hline & & Education & & 0.029 & & .377 & 1.028 \\
\hline & & Nationality & & -0.146 & & .000 & 1.094 \\
\hline & & Residence & & 0.088 & & .008 & 1.069 \\
\hline & & Familiarity & & -0.107 & & .001 & 1.025 \\
\hline 3. & Informedness & TV consumption & .076 & -0.276 & 1,714 & .000 & \\
\hline \multirow[t]{6}{*}{4.} & \multirow[t]{6}{*}{ Informedness } & TV consumption & .135 & -0.209 & 6,696 & .000 & 1.083 \\
\hline & & Gender & -.121 & 0.001 & & 1.030 & \\
\hline & & Education & -.006 & 0.869 & & 1.028 & \\
\hline & & Nationality & .203 & 0.000 & & 1.093 & \\
\hline & & Residence & -.035 & 0.342 & & 1.069 & \\
\hline & & Familiarity & .068 & 0.057 & & 1.025 & \\
\hline
\end{tabular}

Note. TV: television; VIF: variance inflation factor (a multicollinearity test).

Table 3. Breakdown of cultivation effect by country

\begin{tabular}{|c|c|c|c|c|c|}
\hline & & Hungary $(N=170)$ & Czech Republic $(N=259)$ & Poland $(N=93)$ & Slovakia $(N=185)$ \\
\hline DV & IV & & & & \\
\hline Attitude & TV consumption & $0.658^{* *}$ & $1.336^{* *}$ & $0.835^{* *}$ & $1.155^{* *}$ \\
\hline$r^{2}$ & & .049 & .201 & .075 & .162 \\
\hline DV & IV & & & & \\
\hline \multirow[t]{6}{*}{ Attitude } & TV consumption & 0.040 & $0.228 * *$ & 0.050 & $0.261 * *$ \\
\hline & Age & $0.298 * *$ & $0.091 *$ & 0.070 & 0.109 \\
\hline & Gender & $0.199 * *$ & $0.146^{* *}$ & 0.108 & 0.101 \\
\hline & Education & -0.124 & -0.014 & 0.023 & -0.094 \\
\hline & Residence & $0.025 * *$ & -0.025 & 0.117 & 0.043 \\
\hline & Familiarity & $-0.298 * *$ & $0.552 * *$ & $-0.565^{* *}$ & $-0.509 * *$ \\
\hline$r^{2}$ & & .290 & .535 & .412 & .469 \\
\hline
\end{tabular}

Note. The table presents standardized beta coefficients. TV: television; DV: dependent variable; IV: independent variable. ${ }^{*} p<.05 .{ }^{* *} p<.01$. 
Table 4. Legal and cultural contexts - scorings by country

\begin{tabular}{lcccc}
\hline & Czech Republic & Hungary & Poland & Slovakia \\
\hline Cultural context $^{\mathrm{a}}$ & 4 & 3 & 2 & 3 \\
Legal context $^{\mathrm{b}}$ & 4 & 3 & 2 & 3 \\
\hline
\end{tabular}

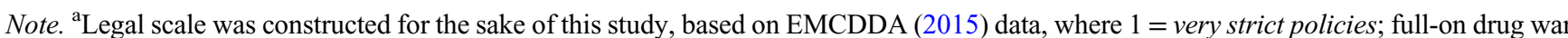
(e.g., Philippines), $2=$ strict policies, $3=$ impassive approach, $4=$ somewhat liberal policies, and $5=$ liberal policies; drugs decriminalized (e.g., Portugal). ${ }^{\mathrm{b}} \mathrm{A}$ culture scale was constructed with the aid of the interviewees, for the aims of this study, where $1=$ hostile predicament toward psychedelics, $2=$ condemnatory cultural context, $3=$ rather indifferent toward psychedelics, $4=$ condoning cultural context, and $5=$ psychedelic-friendly predicament .

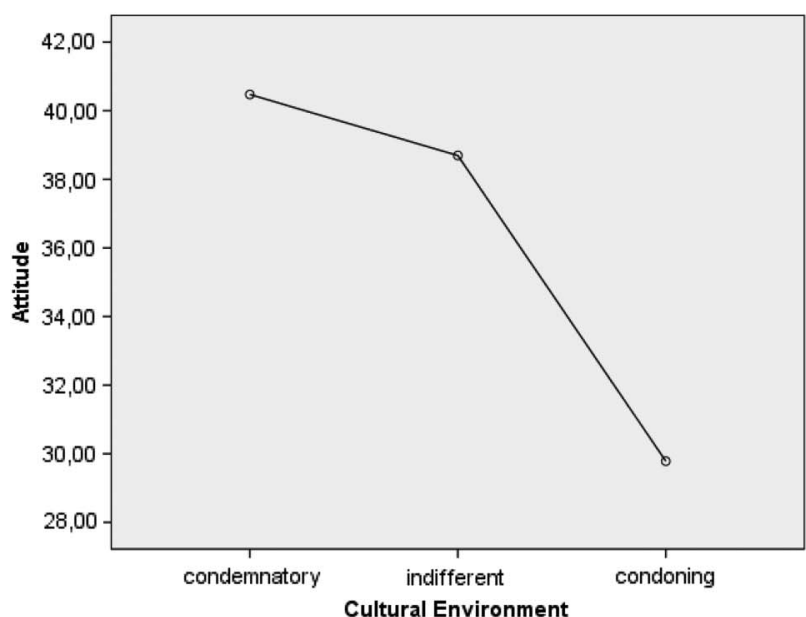

(a)

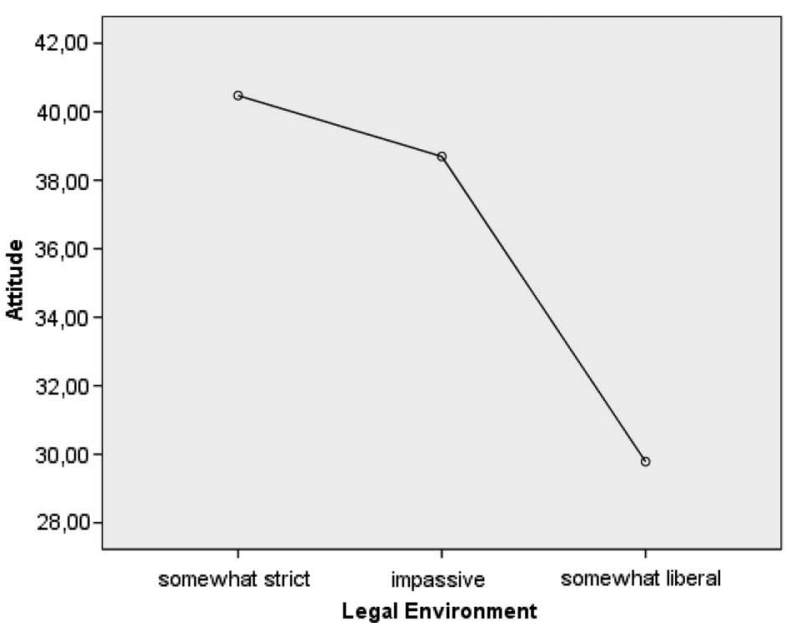

(b)

Figure 1. Means comparison - attitudes toward psychedelics in relation to cultural (a) and legal environments (b)

variables included three groups for cultural environment $(H 3 a)$ : condemnatory $(M=40.47, S D=13.9, N=93)$, indifferent $(M=38.69, S D=12.82, N=353)$, and condoning $(M=29.78, S D=10.02, N=259)$. For legal environment, the three groups were somewhat strict $(M=40.47, S D=13.9$, $N=93)$, impassive $(M=38.69, S D=12.82, \quad N=353)$, and somewhat liberal $(M=29.78, S D=10.02, N=259)$. The assumptions of normality of variance were assessed using histograms and were found tenable for both $H 3 a$ and $H 3 b$, while the homogeneity of variance was assessed using Levene's test for the equality of error variances with $F(2,702)=0.00, p=.00$. The ANOVA was significant in both cases with $F(2,702)=49.55, p=.00$. Thus, there is significant evidence to assume a difference in attitude based on the legal and cultural environments in a given country that is worth further exploring.

Figure 1 demonstrates how participants from different cultural and legal environments scored on the attitude scale, where the $Y$ axis demonstrates the reverse scale of attitude (i.e., the higher the score, the more negative the attitude) and $X$ axis shows the independent variables, respectively. In both cases, the figures show that the friendlier the predicament is in a given country, the less likely are people to form negative attitudes toward psychedelics.

As there could be a number of factors that mitigate or enhance the previously demonstrated relationships, the study further addresses these effects by developing separate models to test the hypotheses individually. In order to examine the third hypotheses using more sophisticated

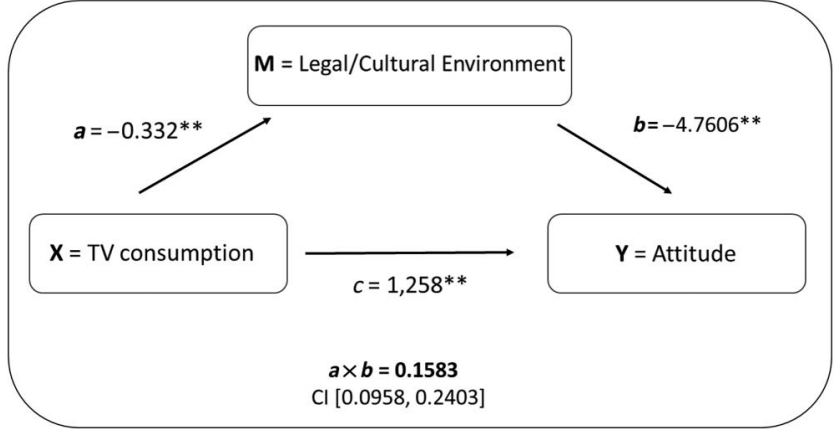

Figure 2. Mediation model - legal/cultural environment's impact on the cultivation effect. ${ }^{*} p<.05 .{ }^{*} p<.01$

methods, the process macro by Hayes (2012) was applied and the first model, classical moderation analysis, was run to test whether the cultural $(\mathrm{H} 3 \mathrm{a})$ or the legal context $(\mathrm{H} 3 \mathrm{~b})$ of the country moderated the cultivation effect. The interaction model fell short of statistical significance with $F(3,701)=$ $89.67, p=.207, r^{2}=.259$ in both cases.

However, upon exploring the relationships, a classical mediation analysis, using the fourth model of the process macro by Hayes (2012) was conducted and a significant mediating impact on the cultivation effect could be observed. As presented in Figure 2, a significant indirect effect of TV on attitude through the legal and cultural environments was detected, where the standardized indirect effect was $a \times b=0.1583$, bias-corrected and accelerated 
confidence interval [0.958, 0.2403], and the mediator accounts for ca. $25 \%$ of the total effect. The significance of this indirect effect was tested using bootstrapping procedures with 5,000 samples, where the unstandardized indirect effect was 0.1583 . Thus, the indirect effect of TV consumption on attitude and the mediating power of legal and cultural environments are shown here to be statistically significant.

These results suggest that a more psychedelic-friendly environment mitigates the enculturation effect of TV, i.e., those who live in countries where the legal and/or cultural context is less hostile are less likely to form negative attitudes toward psychedelics as an effect of TV's cultivation of such narratives.

\section{CONCLUSIONS}

This study argued that the mediatized image of psychedelics affects the public in a way that results in shallow actual knowledge about psychedelics, while promoting a negative opinion toward them. In applying cultivation theory (Gerbner \& Gross, 1976), and leaning on findings by previous researchers of drugs and media (e.g., Belackova et al., 2011; Szasz, 2001), this paper hypothesized that the TV exposure is correlated with $(H 1)$ negative attitudes toward psychedelics, and $(\mathrm{H} 2)$ that the observed effect, while remaining significant, varies across the countries of the Visegrad Alliance.

Relying on quantitative research methods, the aforementioned hypotheses were supported, with the sole influence of TV consumption significant in all countries individually, but only Czech Republic and Slovakia showing a significant effect for TV consumption once control variables (such as demographics and familiarity) were included in the calculations. This is rather an interesting finding, as according to the 2014 survey of Eurobarometer, the citizens of Hungary and Poland were admittedly more reliant on mass media to inform themselves about the risks of drug use. These results might be explained by the different composition of participants in the four countries, due to non-probability sampling.

In Hungary and the Czech Republic, age and gender are both positively significant predictors, i.e., males and younger people tend to have more favorable opinions in these two countries. This could be explained by the esteemed state of psychedelic scientists in pre-prohibition times that is now being rediscovered by junior academics that make up the new generation of psychedelic researchers that are both really only documented in these two of the four studied countries (Chambers, 2014).

Familiarity proved to be the only consistently significant predictor across all countries that underpin findings from scholars on the communications science field who assert that mass media as a primary source of information become more meaningful when direct personal experience is lacking (e.g., Romer, Jamieson, \& Aday, 2003; Schnauber $\&$ Meltzer, 2005). Moreover, this data supports the various changes in personality that have been correlated with the use of psychedelics, including the increase in critical thinking, that empowers viewers to mindfully assess information instead of simply accepting a worldview suggested by mass media (e.g., Nour, Evans, \& Carhart-Harris, 2017).
Thus, based on correlational data, it can be argued that the aggregate of messages transmitted through TV does indeed promote a distorted image of psychedelics that endorses a hostile general attitude toward them. This finding is parallel to what is a frequent topic among psychedelic researchers (e.g., Carhart-Harris et al., 2016) and one that poses important institutional, financial, and reputational challenges on psychedelic science.

The study also hypothesizes that the differences in cultivation effect are moderated by $(H 3 a)$ legal and $(H 3 b)$ cultural contexts. Although these hypotheses were not decidedly supported by the data, a mediation effect of both cultural and legal environments was found. It can, therefore, be argued that both cultural and legal environments carry a mitigating effect on the cultivation phenomena, but do not imply causality. In order to fully comprehend the implications of such correlations, further analysis of such environments with more complex models and additional variables is suggested as a worthwhile topic for future research. Another interesting arena for future research could be a central shortcoming of this study, namely the unexpected identical scoring of countries on the two context scales. Not only would it be useful to conduct more interviews, but the recent (and foreseeable) changes in the conversation around illicit drugs in the region could also bring a more comprehensive outlook on the influence of both predicaments on public attitude and informedness.

It is also important to note that while looking into mass media coverage of controversial societal issues is an important step toward understanding perceptions and the shaping of public opinion (Forsyth, 2001; Körner \& Treloar, 2004), $\mathrm{TV}$ is not the sole influencer of public opinion or conveyer of mass media. Moreover, diverse genres and the nature of different programs on TV have not been differentiated in the analysis of sum of TV consumption and their possibly varying effects have not been explored in this study.

Nevertheless, it is reasonable for this paper to contend that mass media fuels negative bias, while neglects to report on scientific advances regarding psychedelics, resulting in a negative attitude toward ominous substances by those who watch more TV.

Therefore, the results of this project provide insight into how the prevailing narrative in regard to drugs, and particularly psychedelics, affects public opinion that, potentially, serve as justification for prohibitionist drug policies that fuel violence, pose health risks, violate basic human rights, and hold back science (Wolfe, 2013).

The interrelations of media, public opinion, and policy have been studied immensely in communication science (e.g., Kruger \& Wall, 2001; McCombs, 1997) and the (re) emergence of psychedelics, as promising assets in the medical toolkit, justifies the need for a new wave of psychedelic research in social sciences just as well as medical disciplines; there is a wide range of angles and approaches that would help further comprehend the current stigma surrounding psychedelics and eventually be of assistance in restructuring historical, institutional, and moral innervations and reduce associated risks.

The vision of this study is to foster an inclusive, honest dialogue, where current, real, and relevant risks can be 
addressed with an approach (and corresponding toolset) that is more compliant to contemporary circumstances and the actual needs of the affected population.

Acknowledgements: There were no sources of funding for this study. The author would like to thank the interviewed country experts for their valuable contribution and providing insights to national specifics, the colleagues who helped with translations and with disseminating the survey. She would also like to thank her proofreaders, her supervising professor at the University of Vienna and his student assistant for the methodological advice and encouragement throughout the process.

Conflict of interest: The author declares no conflict of interest.

\section{REFERENCES}

Acevedo, B. (2007). Creating the cannabis user. International Journal of Drug Policy, 18(3), 177-186. doi:10.1016/j.drugpo. 2006.11.008

Alper, K. R., \& Lotsof, H. S. (2007). The use of ibogaine in the treatment of addictions. In M. Winkelman \& T. Roberts (Eds.), Psychedelic medicine. New evidences for hallucinogenic substances as treatments (Vol. 2, pp. 43-66). Westport, CT: Preager Perspectives.

Beckett, K., \& Sasson, T. (2004). Defending justice - Crime in the media. Thousand Oaks, CA: Sage.

Belackova, V., Stastna, L., \& Miovsky, M. (2011). 'Selling by drugs': Content analysis of the coverage of illicit drugs in different news media types and formats. Drugs: Education, Prevention and Policy, 18(6), 477-489. doi:10.3109/09687637. 2011.562937

Bissler, D. L., \& Conners, J. L. (Eds.). (2012). The harms of crime media: Essays on the perpetuation of racism, sexism and class stereotypes. Jefferson, NC: McFarland.

Boseley, S. (2016, December 1). Magic mushroom chemical psilocybin could be key to treating depression-studies. The Guardian. Retrieved from https://www.theguardian.com/ society/2016/dec/01/magic-mushroom-ingredient-psilocybincan-lift-depression-studies-show

Burns, W. (2015). LSD microdosing deserves more serious research. Forbes. Retrieved from http://www.forbes.com/sites/ willburns/2015/11/29/1sd-microdosing-deserves-moreserious research/\#1449e30fa763

Brown, D. J. (2013). The new science of psychedelics: At the nexus of culture, consciousness, and spirituality. Rochester, VT: Park Street Press.

Brossard, D., \& Nisbet, M. C. (2007). Deference to scientific authority among a low information public: Understanding US opinion on agricultural biotechnology. International Journal of Public Opinion Research, 19(1), 24-52. doi:10.1093/ ijpor/ed1003

Carhart-Harris, R. L., Erritzoe, D., Williams, T., Stone, J. M., Reed, L. J., Colasanti, A., Tyacke, R. J., Leech, R., Malizia, A. L., Murphy, K., Hobden, P., Evans, J., Feilding, A., Wise, R. G., \& Hobden, P. (2012). Neural correlates of the psychedelic state as determined by fMRI studies with psilocybin.
Proceedings of the National Academy of Sciences of the United States of America, 109(6), 2138-2143. doi:10.1073/ pnas.1119598109

Carhart-Harris, R. L., Muthukumaraswamy, S., Roseman, L., Kaelen, M., Droog, W., Murphy, K., Tagliazucchi, E., Schenberg, E. E., Nest, T., Orban, C., Leech, R., Williams, L. T., Williams, T. M., Bolstridge, M., Sessa, B., McGonigle, J., Sereno, M. I., Nichols, D., Hellyer, P. J., Hobden, P., Evans, J., Singh, K. D., Wise, R. G., Curran, H. V., Feilding, A., \& Nutt, D. J. (2016). Neural correlates of the LSD experience revealed by multimodal neuroimaging. Proceeding of the National Academic Science of the United States of America, 113(17), 4853-4858. doi:10.1073/pnas.1518377113

Chambers, T. (2014). Editor's introduction: Psychedelic resurgence - Research and therapeutic uses, past and present. Journal of Psychoactive Drugs, 46(1), 1-2. doi:10.1080/ 02791072.2014 .874243

Cohen, J., \& Weimann, G. (2000). Cultivation revisited: Some genres have some effects on some viewers. Communication Reports, 13(2), 99-114. doi:10.1080/08934210009367728

Cohen, P. D. A. (1993). Future drug policy in the countries of the former Eastern Bloc: The difficult choice to be non Western. Paper presented at Comunicació presentada en el Colloqui europeu sobre la crisidelssistemesnormatius, París, France. Special UNDCP Fact-finding Mission in Seven Republics of the Commonwealth of Independent States (CIS), UNDCP Vienna 1992, 1-68.

Demetrovics, Z., \& Balázs, H. (2004). Drogosok. In G. Gelsei, V. Gergely, V. Horváth, \& M. Rácz (Eds.), A láthatatlanság vége: társadalomismereti szöveggy jtemény [End of invisibility: A social sciences textbook]. Budapest, Hungary: Alapítvány a Társadalomelméleti Kollégiumért. Retrieved from http://tek. bke.hu/multi/7_drog.pdf

Dowler, K. (2003). Media consumption and public attitudes toward crime and justice: The relationship between fear of crime, punitive attitudes, and perceived police effectiveness. Journal of Criminal Justice and Popular Culture, 10(2), 109-126. Retrieved from https://www.albany.edu/scj/jcjpc/vol10is2/ dowler.pdf

EMCDDA. (2015). EMCDDA yearly drug reports [database]. Retrieved from http://www.emcdda.europa.eu/countries

Forsyth, A. J. M. (2001). Distorted? A quantitative exploration of drug fatality reports in the popular press. International Journal of Drug Policy, 12(5-6), 435-453. doi:10.1016/S0955-3959 (01)00092-5

Gerbner, G. (1970). Cultural indicators: The case of violence in television drama. The Annals of the American Academy of Political and Social Science, 388(1), 69-81. doi:10.1177/ 000271627038800108

Gerbner, G. (1993). The electronic storyteller: Television \& the cultivation of values [video transcript]. Retrieved from http://www.mediaed.org/transcripts/TheElectronic-StorytellerTranscript.pdf

Gerbner, G., \& Gross, L. (1976). Living with television: The violence profile. Journal of Communication, 26(2), 172-194. doi:10.1111/j.1460-2466.1976.tb01397.x

Glasser, T. L., \& Salmon, C. T. (Eds.). (1995). Public opinion and the communication of consent. New York, NY: Guilford Press.

Granfield, R., \& Cloud, W. (1996). The elephant that no one sees: Natural recovery among middle-class addicts. Journal of Drug Issues, 26(1), 45-61. doi:10.1177/002204269602600104 
Hayes, A. F. (2012). PROCESS: A versatile computational tool for observed variable mediation, moderation, and conditional process modeling [White paper]. Retrieved from http:// www.afhayes.com/public/process2012.pdf

Jarnow, J. (2016). LSD now: How the psychedelic renaissance changed acid. Rolling stone. Retrieved from http://www. rollingstone.com/culture/news/lsd-now-how-thepsychedelic renaissance-changed-acid-w443479

Körner, H., \& Treloar, C. (2004). Needle and syringe programmes in the local media: 'Needle anger' versus 'effective education in the community'. International Journal of Drug Policy, 15(1), 46-55. doi:10.1016/S0955-3959(03)00089-6

Krawczyk, D. (2017, May 11). Drugs between East and West: In search of central and eastern European drug policy at UN meeting in Vienna. Retrieved August 06, 2017, from http:// politicalcritique.org/cee/2017/central-and-eastern-europe-unitednationscommission-on-narcotic-drugs-vienna-2017/

Krebs, T., \& Johansen, P.-Ø. (2013). Psychedelics and mental health: A population study. PLoS One, 8(8), e63972. doi:10.1371/ journal.pone.0063972

Kruger, S., \& Wall, P. (2001). AS media studies: The essential introduction. London: Routledge.

Lewis, J. (2001). Constructing public opinion: How political elites do what they like and why we seem to go along with it. New York, NY: Columbia University Press.

Lüscher, C., \& Ungless, M. (2006). The mechanistic classification of addictive drugs. PLoS One, 3(11), e437. doi:10.1371/ journal.pmed.0030437

McCollam, A., O’Sullivan, C., Mukkala, M., Stengård, E., \& Rowe, P. (2008). Mental health in the EU. Key facts, figures, and activities [a background paper]. Retrieved from $\mathrm{http}: / /$ ec.europa.eu/health/ph_determinants/life_style/mental/docs/ background_paper_en.pdf

McCombs, M. (1997). Building consensus: The news media's agenda-setting roles. Political Communication, 14(4), 433-443. doi:10.1080/105846097199236

Morgan, M., Shanahan, J., \& Signorielli, N. (Eds.). (2012). Living with television now: Advances in cultivation theory \& research. New York, NY: Peter Lang.

Nielsen (2010). Three screen report. Retrieved from http://www. nielsen.com/us/main/insights/nielsen_a2m2_three

Nichols, D. (1999/2000, Winter). From Eleusis to PET scans: The mysteries of psychedelics. MAPS, 9(4), 50-55.

Nichols, D. E. (2016). Psychedelics. Pharmacological Reviews, 68(2), 264-355. doi:10.1124/pr.115.011478

Noto, A. R., Pinsky, I., \& Mastroianni, F. D. C. (2006). Drugs in the Brazilian print media: An exploratory survey of newspaper and magazine stories in the year 2000. Substance Use \& Misuse, 41(9), 1263-1276. doi:10.1080/10826080 600754868
Nour, M. M., Evans, L., \& Carhart-Harris, R. L. (2017). Psychedelics, personality and political perspectives. Journal of Psychoactive Drugs, 49(3), 182-191. doi:10.1080/02791072. 2017.1312643

OECD. (2017). Suicide rates [OECD database]. Retrieved June 17, 2017, from https://data.oecd.org/healthstat/suiciderates.htm

O'Neill, S. (2014). Psychedelic science: The surge in psychiatric research using hallucinogens. Pasadena, CA: American Public Media, Southern California Public Radio Archives.

Romer, D., Jamieson, K. H., \& Aday, S. (2003). Television news and the cultivation of fear of crime. Journal of Communication, 53(1), 88-104. doi:10.1111/j.1460-2466.2003.tb03007.x

Rothstein, R. A , \& Finnigan, R. (2015). Marijuana \& the media: The influence of media narratives on legalization outcomes. UC Davis, 1-44.

Schnauber, A., \& Meltzer, C. E. (2015). The impact of personal experience in cultivation. SCM Studies in Communication and Media, 4(1), 7-27. doi:10.5771/2192-4007-2015-1-7

Schoenbach, K., \& Becker, L. B. (1995). Origins and consequences of mediated public opinion. In T. L. Glasser \& C. T. Salmon (Eds.), Public opinion and the communication of consent (pp. 323-347). New York, NY: Guilford Press.

Sewell, R. A. (2006). So you want to be a psychedelic researcher? The Entheogen Review, 15(2). Retrieved from https://erowid. org/psychoactives/research/research_psychedelic_article1.pdf

Surette, R. (1992). Media, crime, and criminal justice: Images and realities. Pacific Grove, CA: Brooks/Cole Publishing Company.

Szasz, T. (2001). Szertartásos kémia- Drogmitológiák [Ceremonial chemistry - Drugmithodologies]. Budapest, Hungary: Új Mandátum.

Vollenweider, F. X., \& Kometer, M. (2010). The neurobiology of psychedelic drugs: Implications for the treatment of mood disorders. Nature Reviews. Neuroscience, 11(9), 642. doi:10.1038/ $\operatorname{nrn} 2884$

Welch, M., Fenwick, M., \& Roberts, M. (1998). State managers, intellectuals, and the media: A content analysis of ideology in experts' quotes in feature newspaper articles on crime. Justice Quarterly, 15(2), 219-241. doi:10.1080/074188298000 93721

Williams, L. (1999). Human psychedelic research: A historical and sociological analysis (Undergraduate thesis). History and Philosophy of Science, Cambridge University, Cambridge, UK.

Wolfe, D. (2013). Is the INCB dangerous to your health? 5 ways the UN's drug watchdog fails on health and human rights. Retrieved on August 20, 2017, from https://www.opensociety foundations.org/voices/incb-dangerous-your-health-5-ways-uns drug-watchdog-fails-health-and-human-rights 


\section{APPENDIX}

Table A1. Summary of legal and cultural environments per country

\begin{tabular}{|c|c|c|c|c|}
\hline & Hungary & Czech Republic & Poland & Slovakia \\
\hline \multirow[t]{7}{*}{$\begin{array}{l}\text { Cultural context } \\
\text { summary }\end{array}$} & $\begin{array}{r}\text { - Historically socially } \\
\text { conservative attitude }\end{array}$ & - "we have an OK situation" & - "sobering situation" & $\begin{array}{l}\text { - Small but close-knit } \\
\text { psytrance scene and a small } \\
\text { psychedelic society paving } \\
\text { the way for science }\end{array}$ \\
\hline & $\begin{array}{l}\text { - Abstinence-based harm- } \\
\text { reduction measures and no } \\
\text { support for peer-led initiatives }\end{array}$ & $\begin{array}{l}\text { - More and more measures are } \\
\text { implemented toward keeping } \\
\text { people safe rather than } \\
\text { criminalizing them }\end{array}$ & $\begin{array}{l}\text { - Moral understanding of } \\
\text { addiction }\end{array}$ & $\begin{array}{l}\text { - Science is still lagging, many } \\
\text { ethical obstacles }\end{array}$ \\
\hline & $\begin{array}{l}\text { - Small but tight community on } \\
\text { the psychedelic scene }\end{array}$ & $\begin{array}{l}\text { - Law enforcement does not } \\
\text { target users }\end{array}$ & $\begin{array}{l}\text { - Anyone can be stripped of their } \\
\text { basic human rights if they are } \\
\text { deemed a "junkie" }\end{array}$ & $\begin{array}{l}\text { - Decreasing volume of harm- } \\
\text { reduction services }\end{array}$ \\
\hline & $\begin{array}{l}\text { - Iconic festivals, self organized, } \\
\text { trusted harm reduction services }\end{array}$ & $\begin{array}{l}\text { - Tradition of psy-parties and } \\
\text { festivals: psychedelic } \\
\text { pilgrimages }\end{array}$ & $\begin{array}{l}\text { - Most parties lack basic harm- } \\
\text { reduction measures }\end{array}$ & $\begin{array}{l}\text { - No systematical support for } \\
\text { education or HR }\end{array}$ \\
\hline & $\begin{array}{l}\text { - Law enforcement sometimes } \\
\text { targets HR providers and } \\
\text { people who use drugs, } \\
\text { especially minorities }\end{array}$ & $\begin{array}{l}\text { - Nothing specifically } \\
\text { stigmatizing in the media, } \\
\text { mostly not positive, but a } \\
\text { "personal choice" is } \\
\text { emphasized }\end{array}$ & $\begin{array}{l}\text { - Psychedelics are amiss from } \\
\text { the academic discourse }\end{array}$ & $\begin{array}{l}\text { - Metamphetamines are } \\
\text { "overshadowing" } \\
\text { psychedelics on the } \\
\text { recreational scene }\end{array}$ \\
\hline & $\begin{array}{l}\text { - No formal scientific } \\
\text { community, but more and more } \\
\text { interested young researchers }\end{array}$ & $\begin{array}{l}\text { - Moderate stigma on drugs in } \\
\text { general with a moderate } \\
\text { acknowledgment of their } \\
\text { miscellaneous scientific } \\
\text { properties }\end{array}$ & $\begin{array}{l}\text { - No known psychedelic } \\
\text { scientists or public figures } \\
\text { talking about it }\end{array}$ & $\begin{array}{l}\text { - Law enforcement does not } \\
\text { typically target users }\end{array}$ \\
\hline & $\begin{array}{l}\text { - Some internationally renowned } \\
\text { academics } \\
\text { - Very controversial, mostly } \\
\text { stigmatizing image in media }\end{array}$ & $\begin{array}{l}\text { - Blooming research in mental } \\
\text { health }+ \text { historical figures }\end{array}$ & $\begin{array}{l}\text { - Mediatized narrative: "drugs } \\
\text { are bad, they make people } \\
\text { crazy and violent, users are } \\
\text { dangerous, addicts are poor } \\
\text { and stupid" }\end{array}$ & $\begin{array}{l}\text { - Hippie stigma, but not much } \\
\text { media attention }\end{array}$ \\
\hline $\begin{array}{l}\text { Cultural context } \\
\text { score }^{\mathrm{a}}\end{array}$ & 3 & 4 & 2 & 3 \\
\hline \multirow[t]{2}{*}{$\begin{array}{l}\text { Legal context } \\
\text { summary }\end{array}$} & $\begin{array}{l}\text { - Consumption and possession is } \\
\text { a criminal offense, punishable } \\
\text { by up to } 2 \text { years in prison (and } \\
5-10 \text { and } 5-15 \text { years if } \\
\text { involving larger quantities) }\end{array}$ & $\begin{array}{l}\text { - Drug use is not a criminal } \\
\text { offense }\end{array}$ & $\begin{array}{l}\text { - Any drug possession is a } \\
\text { criminal offense and is } \\
\text { penalized with up to } 3 \text { years } \\
\text { imprisonment }\end{array}$ & $\begin{array}{l}\text { - Possession for personal use is } \\
\text { a criminal offense, punishable } \\
\text { up to } 3 \text { years imprisonment } \\
\text { (the court may suspend } \\
\text { execution of a sentence not } \\
\text { longer than } 3 \text { years for minor } \\
\text { supply offenses, if the } \\
\text { offender is addicted and the } \\
\text { treatment appears to have a } \\
\text { chance of success + } \\
\text { alternative penalties to } \\
\text { imprisonment, if prior } \\
\text { behavior and other } \\
\text { circumstances suggest.) }\end{array}$ \\
\hline & $\begin{array}{l}\text { - Supply is punishable if } \\
\text { involving a small amount: } \\
1-5 \text { years, } 5-20 \text { years, or life if } \\
\text { involving certain } \\
\text { circumstances or large } \\
\text { quantities }\end{array}$ & $\begin{array}{l}\text { - Possession of small quantities } \\
\text { for personal use is an } \\
\text { administrative offense (fine) }\end{array}$ & $\begin{array}{l}\text { - Trafficking of drugs is } \\
\text { penalized by a fine and } \\
\text { imprisonment of between } \\
6 \text { months and } 8 \text { years }\end{array}$ & $\begin{array}{l}\text { - Possession of any amount } \\
\text { above " } 10 \text { doses" must be } \\
\text { charged under drug } \\
\text { trafficking, supply or } \\
\text { production with a penalty of } \\
\text { 3-10 years imprisonment }\end{array}$ \\
\hline
\end{tabular}


Table A1. (Continued)

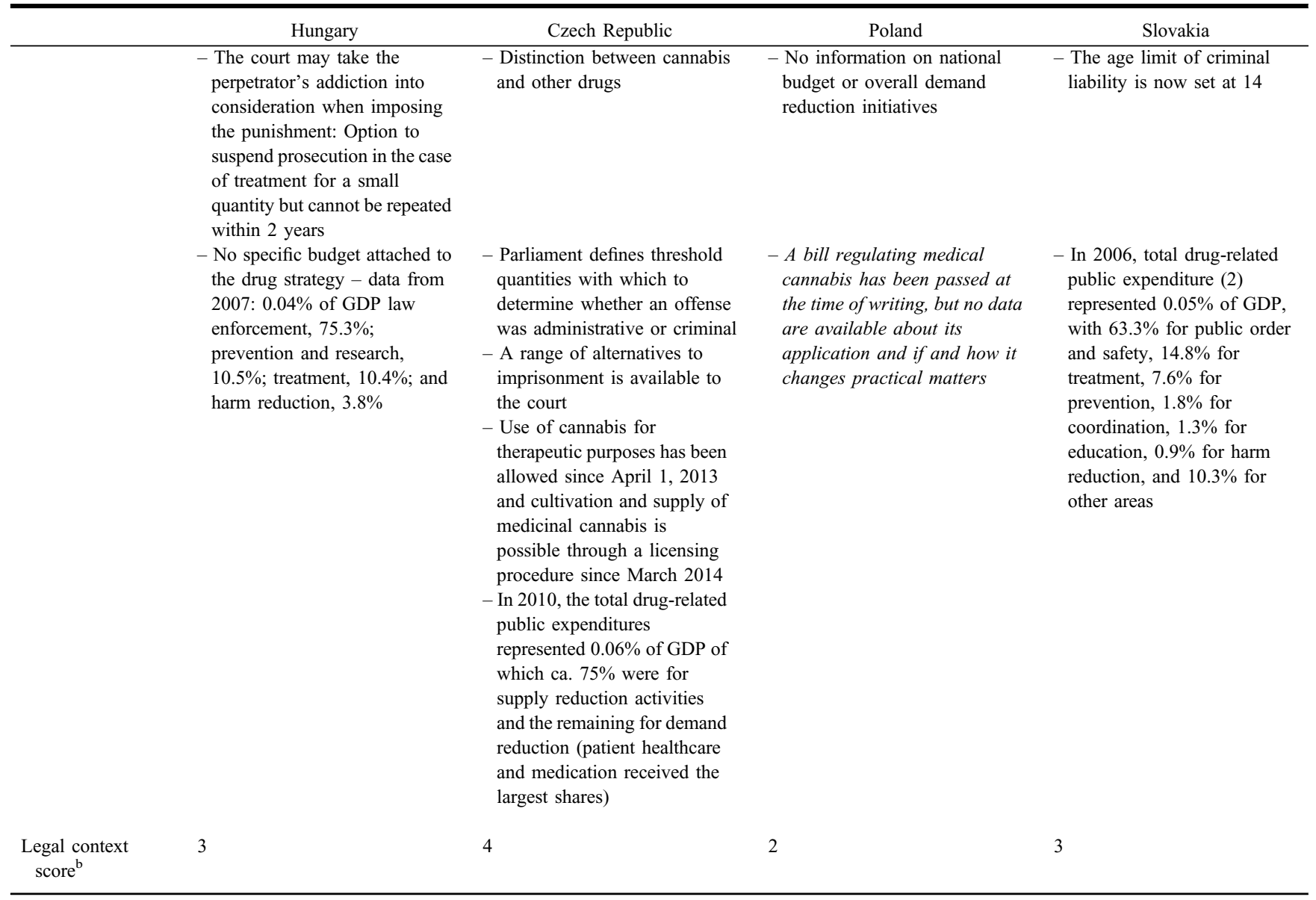

Note. GDP: gross domestic product.

${ }^{a}$ Legal scale was constructed for the sake of this study, where $1=$ very strict policies, (such as the Philippines, for example) and $5=$ liberal policies (such as Portugal).

${ }^{\mathrm{b}} \mathrm{A}$ culture scale was constructed with the aid of the interviewees, for the aims of this study, where $1=$ hostile predicament and $5=$ psychedelic-friendly environment. 